\title{
Double-resonance in alkali vapor cells for high performance and miniature atomic clocks
}

\author{
Thejesh Bandi, Matthieu Pellaton, Danijela Miletic, \\ Christoph Affolderbach, Florian Gruet, Renaud Matthey, \\ and Gaetano Mileti
}

\author{
Laboratoire Temps - Fréquence (LTF) \\ Institut de Physique, Université de Neuchâtel \\ 2000 - Neuchâtel, Switzerland \\ Email: gaetano.mileti@unine.ch
}

\author{
Camillo Stefanucci, Maddalena Violetti, \\ Francesco Merli, Jean-François Zürcher \\ and Anja K. Skrivervik \\ Laboratoire d'Electromagnétisme et d'Acoustique (LEMA), \\ École Polytechnique Fédérale de Lausanne (EPFL), \\ 1015 - Lausanne, Switzerland
}

\begin{abstract}
We present two lines of investigations on vapor cell based laser-microwave double-resonance (DR) rubidium atomic frequency standards: a compact high-performance clock exhibiting $\sigma_{\mathrm{y}}(\tau)<1.4 \times 10^{-13} \tau^{-1 / 2}$ and a miniaturized clock with $\sigma_{\mathrm{y}}(\tau)<1 \times 10^{-11} \tau^{-1 / 2}$. The applications of these standards are emphasized towards portable applications such as next generation GNSS, deep space missions and telecommunications. Other techniques for DR clocks are discussed in brief.
\end{abstract}

\section{INTRODUCTION}

In recent years, laser optical-pumping has substantially improved the achievable frequency stabilities of rubidium cell standards [1-4]. The compactness of these standards is beneficial in view of portable applications, such as GNSS, telecommunications etc.

Last developments on high-performance $\mathrm{Rb}$ standards have resulted in stabilities better than the lamp-pumped $\mathrm{Rb}$ clocks, cesium beam standards and passive hydrogen masers [3-7]. In this paper we will discuss the continuous-wave (CW) optical pumping approach to $\mathrm{Rb}$ standards. In contrast to other approaches as for example pulsed optical pumping (POP), the $\mathrm{CW}$ approach has the advantage of not requiring an acoustooptical-modulator (AOM) or any other light shutters for the clock operation [4]. Only a small and simple laser source is sufficient. Hence, the compactness of high-performance $\mathrm{Rb}$ standards is not compromised, while they still can achieve excellent stabilities of $<2 \times 10^{-13} \tau^{-1 / 2}$.

The developments of miniaturized frequency references are of particular relevance considering certain portable applications, for instance in telecommunications or for military purposes. So far the major focus in miniaturized clocks was on using coherent population trapping (CPT) scheme [8-10]. In comparison, the double-resonance approach has several advantages. Thanks to the absence of non-resonant laser modulation sidebands, the background level of the signal is reduced. In addition, it allows a ten times higher amplitude with degradation of the linewidth by only a factor of two. Therefore, in similar operating conditions, DR allows a typically five times better short-term stability [11].

This paper focusses on the two above mentioned approaches: the high-performance- and the miniaturized rubidium standards in a CW laser-microwave DR scheme, both based on $\mathrm{Rb}$ cells containing thermal atomic vapors. At first, the DR operation principle is recalled for ${ }^{87} \mathrm{Rb}$ atoms. The building blocks of our high-performance clocks, such as glass-blown cells, laser source and compact microwave cavities are then discussed. The physics packages (PP) are presented with their respective achieved stabilities. In a second approach we focus on the use of microfabricated miniaturized cells and on the microwave cavity. DR signals and an excellent stability $\left(<1 \times 10^{-11} \tau^{-1 / 2}\right)$ are shown and discussed for this clock. Finally, we present other alternative technologies, such as the use of wall-coatings, low-temperature bonding and microfabricated $\mathrm{Rb}$ discharge lamps.

\section{CLOCK PRINCIPLE AND KEY BUILDING BLOCKS}

\section{A. Clock principle}

The continuous-wave laser-microwave double-resonance principle requires two sources of radiation resonant with $\mathrm{Rb}$ atomic transitions: the laser and the microwave source. The light emitted by the laser optically pumps the vapor of the rubidium atoms, thus depleting one of the ground states and populating the other one, i.e. creating a polarization of the atomic ground-state as shown in Fig. 1. Simultaneously, a microwave field is applied. Its frequency, resonant with the ${ }^{87} \mathrm{Rb}$ clock transition $\left(5^{2} \mathrm{~S}_{1 / 2}\left|\mathrm{~F}_{\mathrm{g}}=1, \mathrm{~m}_{\mathrm{F}}=0\right\rangle \rightarrow\left|\mathrm{F}_{\mathrm{g}}=2, \mathrm{~m}_{\mathrm{F}}=0\right\rangle\right)$, is generated by a voltage controlled crystal oscillator whose frequency is multiplied. The light power transmitted through the cell, as a function of the microwave frequency, is a measure of the atomic ground-state polarization and gives the clock signal. This signal typically has a Lorentzian shape

This work was supported by the Swiss National Science Foundation (SNSF grants: 200020 118062, 200020_130381, Sinergia CRSI20_122693, R'Equip 206021, the Swiss Space Office (SER-SSO), and the European Space Agency (ESA). 
$[1,3]$, and stabilization of the quartz oscillator to the center of this signal realizes the clock.

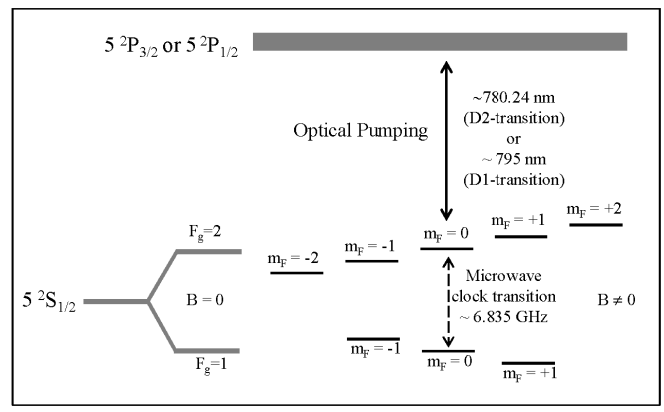

Figure 1. Principle of double-resonance (DR) spectroscopy depicted using ${ }^{87} \mathrm{Rb}$ atomic energy-level scheme.

\section{B. Glass-blown buffer-gas cells}

Examples of glass-blown $\mathrm{Rb}$ cells used in our highperformance clocks are shown in Fig. 2. These cells are filled with metallic ${ }^{87} \mathrm{Rb}$ and a mixture of buffer gases (BG) at our in-house cell filling facility. Buffer gases are used in order to avoid the wall-collisions, increase the resonance line Q-factor by Dicke narrowing [12], and reduce light-shift effects and the temperature sensitivity of the clock frequency $[1,13]$.

$14 \mathrm{~mm}$ diameter cells, similar to those commonly used in commercial rubidium atomic frequency standards were studied in a laser-noise-cancellation clock scheme [14]. However, larger dimensions of the cell are interesting for achieving a higher atomic Q-factor and allow interrogating a larger number of atoms at low atomic density and light intensities, and hence a better signal-to-noise $(\mathrm{S} / \mathrm{N})$ ratio. This improves the short-term frequency stability of the clock. Upper limits for the cell dimensions of $25 \mathrm{~mm}$ diameter are physically set by the compact cavity design [15].

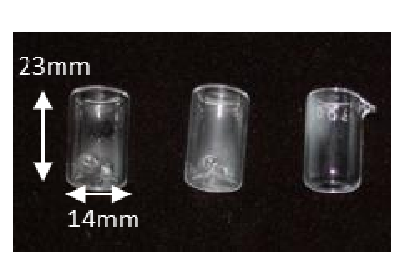

(a)

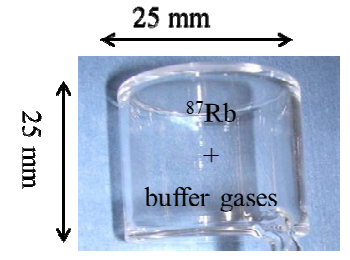

(b)
Figure 2. Glass-blown cells with two different dimensions; (a) $14 \mathrm{~mm} \mathrm{x}$ $23 \mathrm{~mm}$ and (b) $25 \mathrm{~mm} \times 25 \mathrm{~mm}$, filled with ${ }^{87} \mathrm{Rb}$ and a mixture of buffer gases.

\section{Laser sources}

The $780 \mathrm{~nm}$ (Rb D2-line) or $795 \mathrm{~nm}$ (Rb D1-line) pump light is provided from a compact laser head $[2,6]$ shown in Fig. 3(a). The compact laser head has an overall volume of $<0.75 \mathrm{dm}^{3}$ and a mass of $<0.6 \mathrm{~kg}$. The laser head used here includes a DFB laser diode and a small Rb spectroscopy setup for laser frequency stabilization, in an optical physics package of $0.2 \mathrm{dm}^{3}$ volume. The DFB laser diode is operated around ambient temperature and $100 \mathrm{~mA}$ injection current, with wide mode-hop free tuning range around these values. Threshold current is around $40 \mathrm{~mA}$.

The laser diodes used have wavelength tuning coefficients with laser current and temperature of $-1 \mathrm{GHz} / \mathrm{mA}$ and -
$25 \mathrm{GHz} / \mathrm{K}$, respectively. They show single mode operation with a Side-Mode Suppression Ratio (SMSR) $>40 \mathrm{~dB}$. Relative Intensity Noise (RIN) at $300 \mathrm{~Hz}$ is measured to be $7 \times 10^{-14} \mathrm{~Hz}^{-1}$, and frequency noise at the same Fourier frequency is $4 \mathrm{kHz} / \sqrt{\mathrm{Hz}}$; both are sufficiently low not to degrade the clock's short-term stability. The laser linewidth is $\approx 5 \mathrm{MHz}$ (at $100 \mathrm{~mA}$ injection current), measured by beat-note with an identical laser head assembly.

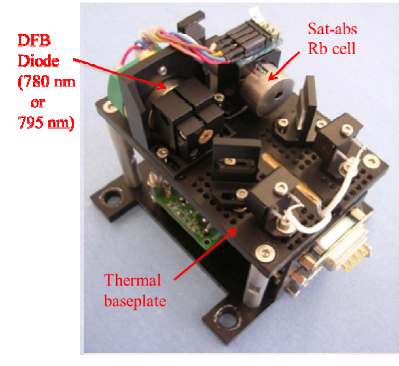

(a)

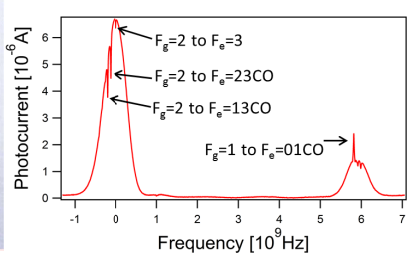

(b)
Figure 3. (a) Compact, stabilized laser head, dimensions are $9 \times 9 \times 10 \mathrm{~cm}$; (b) $\mathrm{Rb}$ saturated absorption spectra showing the transitions to which laser can be stabilized.

The laser frequency is stabilized to saturated-absorption lines (shown in Fig. 3(b)) obtained from a small $(10 \mathrm{~mm}$ diameter, $19 \mathrm{~mm}$ length) rubidium cell filled at LTF with enriched ${ }^{87} \mathrm{Rb}$. The frequency stability was evaluated by recording the beat note signal between two laser heads. The short-term stability $(1<\tau<4,000 \mathrm{~s})$ is $<6 \times 10^{-12} \tau^{-1 / 2}$ and the frequency stability between $4,000 \mathrm{~s}<\tau<1$ day is $<4 \times 10^{-12}$, which is sufficient to maintain the clock's instability below $1 \times 10^{-14}$ level at 1 day time-scales. The aging of DFBs was evaluated during 9 months by measuring the injection current required to maintain a constant optical frequency [16]. An extrapolation of this study to a 20 years operation shows the potential of DFB in replacement of discharge lamps in cell's frequency standards. For further details on the laser head including the long-term tests and evaluations see $[2,4,6,13$, 16].

\section{Compact microwave cavites}

For our clocks we use Loop Gap Resonator (LGR) cavities or microwave resonators (MWR) tuned at $6.835 \mathrm{GHz}$; these are very compact and have volumes at least a factor of 3 smaller than traditional cylindrical cavities with $\mathrm{TE}_{011}$ mode. The outer diameters of both of the cavities, accommodating $14 \mathrm{~mm}$ and $25 \mathrm{~mm}$ diameter cells, are $24 \mathrm{~mm}$ and $40 \mathrm{~mm}$, respectively (see Fig. 4). For further details on $25 \mathrm{~mm}$ cavities see [15].

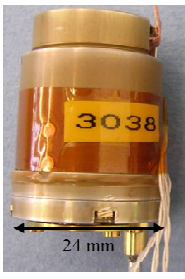

(a)

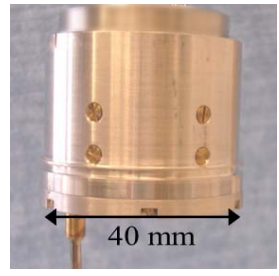

(b)
Figure 4. Compact LGR microwave cavities with TE011 mode, (a) accommodating $14 \mathrm{~mm}$ diameter cell and (b) accommodating $25 \mathrm{~mm}$ diameter cell. 
The cavities are surrounded by $\mathrm{C}$-field coils that generate magnetic fields oriented parallel to laser propagation direction. These fields are used to split the degenerated hyperfine-levels to their corresponding Zeeman sub-levels [1]. The whole assembly including the cell, LGR, coil and heaters is enclosed inside magnetic shields. This entire assembly is termed as the clock's atomic resonator package.

\section{E. Microwave source and control electronics}

The short-term clock stability can be limited by the intermodulation effect (Dick effect). Thus an important factor, especially for high-performance clocks is the phase noise of the microwave source or Local Oscillator (LO). For our studies we used a low phase-noise synthesizer generating a stable $6.835 \mathrm{GHz}$ frequency with an output power $\sim 10 \mathrm{dBm}$ that is described in detail in [17]. Its phase noise at the $6.835 \mathrm{GHz}$ carrier is measured to be $S_{\varphi}(\mathrm{f})=-108 \mathrm{dBrad}^{2} / \mathrm{Hz}$ (a) $300 \mathrm{~Hz}$. From this value, its contribution to the clock instability via the intermodulation effect is estimated to be $\approx$ $8 \times 10^{-14}$ at $1 \mathrm{~s}$ integration time.

We used in-house made temperature control modules based on digital electronics for the resonator packages and the laser heads. Low-noise current drivers and lock-in loops for the laser heads operation were also realized at LTF.

\section{HIGH PERFORMANCE LASER-PUMPED RB CLOCKS}

\section{A. Laser-noise cancelled clock (14 $\mathrm{mm}$ cell)}

The $14 \mathrm{~mm}$ cell clock has enabled the development of necessary technologies towards a very compact laser-pumped $\mathrm{Rb}$ clock, and finally has demonstrated the feasibility of reaching very competitive frequency stabilities from a core resonator package of $1.1 \mathrm{dm}^{3}$ volume only. This clock uses a noise subtraction technique based on two identical resonator packages to reduce the impact of laser FM-to-AM noise conversion on the clock's short-term stability [13, 14]. Fig. 5 shows this fully assembled clock demonstrator, including two resonator packages for noise subtraction (right-hand side) and the laser module (left-hand side). This integrated laser module has the same working principle as already explained in section II.C. Both, laser module and resonator packages are mounted on one common, thermostated baseplate; the overall PP weighs around $2 \mathrm{~kg}$. At this development stage, laboratory electronics were used.

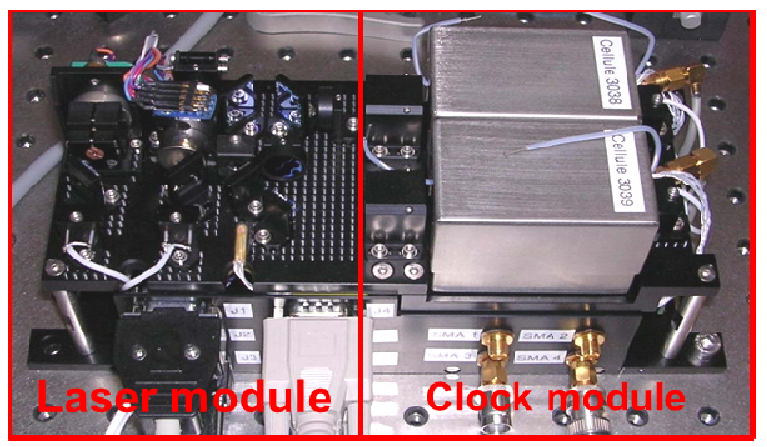

Figure 5. Photograph of the fully assembled clock demonstrator with integrated laser- and clock module with two resonator packages using $14 \mathrm{~mm}$ cells.
The DR signals obtained from this demonstrator typically have $0.57 \mu \mathrm{A}$ in amplitude, linewidth (FWHM) of $980 \mathrm{~Hz}, 7 \%$ contrast (defined as the amplitude divided by the background) and a discriminator slope of $583 \mathrm{pA} / \mathrm{Hz}$ (see [13] for details).

When using the noise subtraction technique, the short-term stability is reduced from $1.1 \times 10^{-12} \tau^{-1 / 2}$ (using one resonator package only) to $5.3 \times 10^{-13} \tau^{-1 / 2}$ (with laser FM-AM noise subtraction), which is very close to the shot-noise limit of $4.5 \times 10^{-13} \tau^{-1 / 2}$ (Fig. 6). The medium- to long-term stability of this clock reaches $\leq 3 \times 10^{-14}$ at $\tau>20,000 \mathrm{~s}$ [13], which is an excellent result for a clock not operated under vacuum.

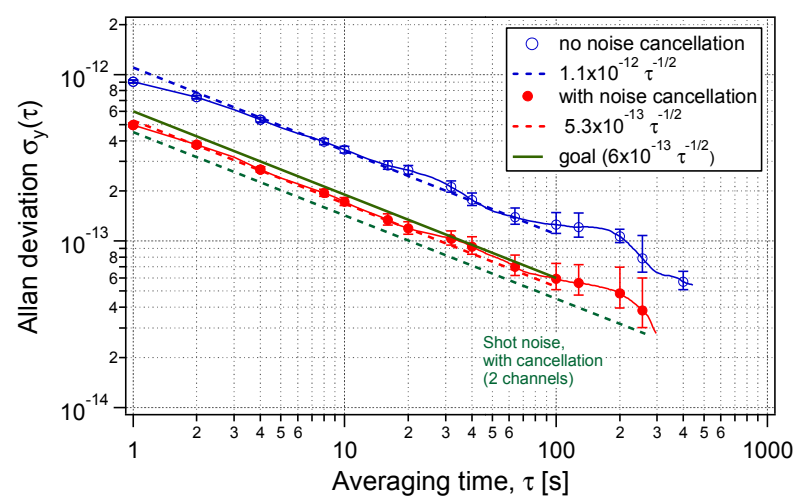

Figure 6. $14 \mathrm{~mm}$ cell clock stabilities; shown with and without noise subtraction technique.

\section{B. Enlarged cell clock $(25 \mathrm{~mm}$ cell $)$}

The motivation towards using larger cells to obtain a narrower signal was explained in the section II.B. In this case the resonator package consists of $25 \mathrm{~mm}$ x $25 \mathrm{~mm}$ cell filled with enriched ${ }^{87} \mathrm{Rb}$ and mixture of buffer gases (Fig. 2(b)). The cell is placed inside the LGR (Fig. 4(b)) that is tuned to the $\mathrm{Rb}$ clock transition. The LGR has a volume of $\leq 40 \mathrm{~cm}^{3}$ [15]. The fully mounted resonator package having a volume of $<0.8 \mathrm{dm}^{3}$ and a mass of less than $1.4 \mathrm{~kg}$ is shown in Fig. 7.

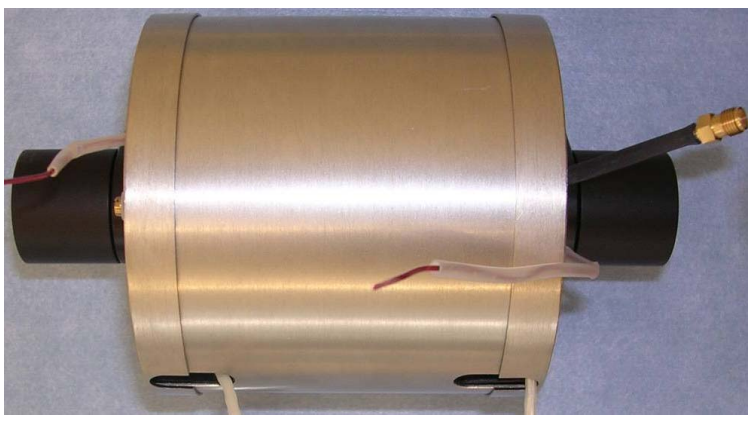

Figure 7. Fully assembled resonator package with $25 \mathrm{~mm}$ diameter cell.

Fig. 8 shows a typical DR signal measured using this resonator package. It has a FWHM of $333 \mathrm{~Hz}$, a signal contrast of $25 \%$ and a discriminator slope of $1.43 \mathrm{nA} / \mathrm{Hz}$. The photocurrent of $1.6 \mu \mathrm{A}$ at half-amplitude of the DR signal sets a shot-noise limit to $5 \times 10^{-14} \tau^{-1 / 2}$ [3]. However, presently the $\mathrm{S} / \mathrm{N}$ limited stability of our clock is estimated at $1.7 \times 10^{-13} \tau^{-1 / 2}$, mainly due to laser FM-to-AM noise conversion in the atomic vapor $[18,19]$. 


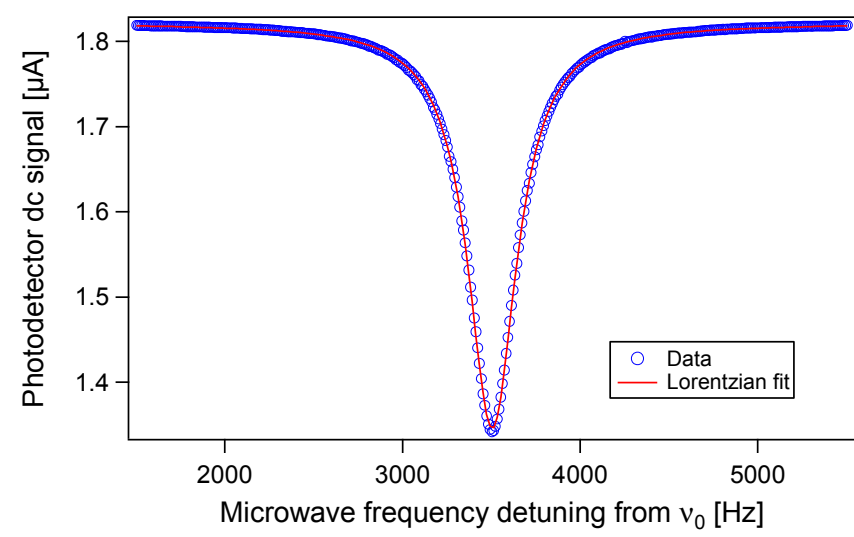

Figure 8. DR signal with $25 \mathrm{~mm}$ cell. $v_{0}$ is the ${ }^{87} \mathrm{Rb}$ unperturbed clock frequency.

The measured short-term frequency stability of our clock is $1.36 \times 10^{-13} \tau^{-1 / 2}$ (see Fig. 9), which is in a good agreement with the predicted $\mathrm{S} / \mathrm{N}$ limit. This clock was operated in standard laboratory conditions (no vacuum enclosure or thermal chambers used). Studies on the medium- to long-term time-scales ( $\tau \geq 100 \mathrm{~s}$ ) remain to be done by evaluating, for instance, the impact of light-shifts, temperature shifts, and microwave power shifts. However, a similar resonator package, with a different cavity, showed stabilities of $<1 \times 10^{-14}$ at $10^{4}$ s up to 1 day [3].

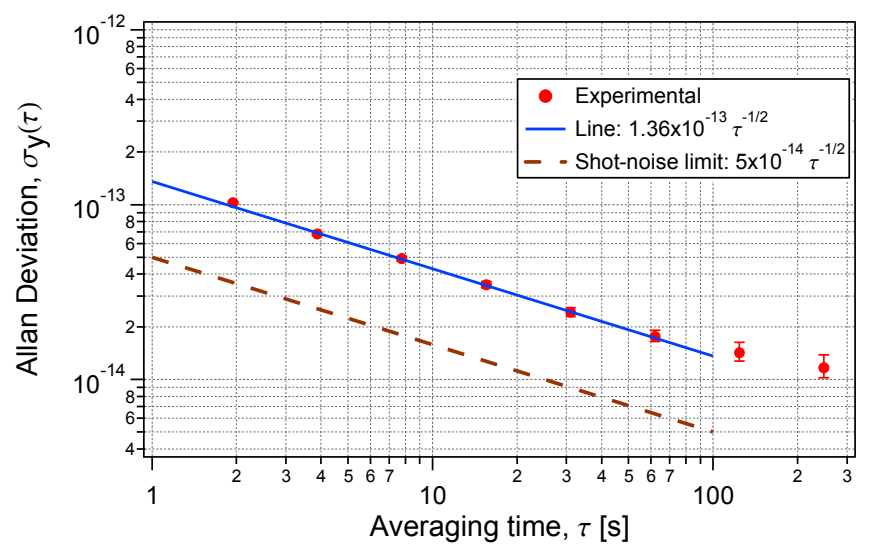

Figure $9.25 \mathrm{~mm}$ cell clock short-term stability without noise cancellation.

We have demonstrated that by using a larger cell, we could improve the short-term stability and reach the level of $<1.4 \times 10^{-13} \tau^{-1 / 2}$. This short-term stability is comparable to the pulsed-optical-pumping clock operated under vacuum [4], and is about a factor of five better than for a passive H-maser [5]. This stability is also approximately one order of magnitude better than the best lamp-pumped Rb clocks. Furthermore, using the noise subtraction technique, we expect to reach the level of $<1 \times 10^{-13} \tau^{-1 / 2}$.

\section{DOUBLE RESONANCE WITH MICROFABRICATED CELLS}

\section{A. $2 D$ and $3 D$ microfabricated cells and $\mu-L G R$}

The potential of a DR clock using a microfabricated alkali vapor cell (2D-cell with the inner dimensions of $5 \mathrm{~mm}$ in diameter and a height of $2 \mathrm{~mm}$, see Figure 10(a)) filled with buffer gas was already demonstrated [20, 21]. The corresponding clock's Allan deviations using laboratory electronics were measured to be $6 \times 10^{-11} \tau^{-1 / 2}$ and $<2 \times 10^{-11} \tau^{-1 / 2}$, respectively.

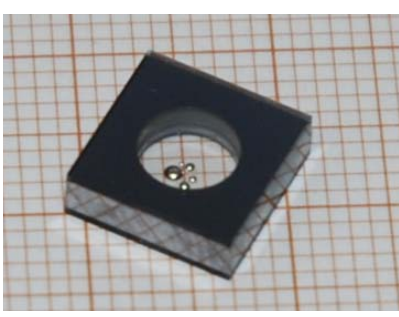

(a)

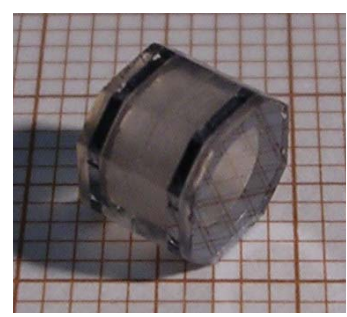

(b)
Figure 10. Microfabricated cells; (a) 2D cell and (b) 3D cell. The mm-scale paper in the background gives the idea of scaling for the cell dimensions.

To further improve the performances and in view of future miniature DR clocks, a new miniature cell (3D-cell) was designed and microfabricated in collaboration with SAMLABEPFL [22]. The goal of 3D-cell was to increase the vapor thickness and thus to improve on the DR signal. The cell design was also driven by the parallel development of a new generation of microwave loop gap resonators, or $\mu$-LGR [23] (see Fig. 11). The 3D-cell shown in Figure 10(b) has inner dimensions of $4 \mathrm{~mm}$ in diameter and $4.05 \mathrm{~mm}$ in height. It consists of a multiple stack of glass and silicon layers bonded to each other using anodic bonding [9]. The cavity inside the thick glass layer is mechanically drilled, while silicon is patterned by deep reactive ion etching (DRIE).

The $\mu$-LGR is a multi-layer stack of printed loop-gap resonator structures, coupled to a coaxial fed strip-line (see Figure 11). This structure has a total cavity volume $<0.9 \mathrm{~cm}^{3}$ and within the cell volume, $90 \%$ of the total sustained magnetic field is parallel to the laser beam axis. Two screws mounted into the microwave resonator metallic enclosure (not shown) and inserted into the cavity allow the fine tuning of the resonant frequency to the ${ }^{87} \mathrm{Rb}$ clock transition.

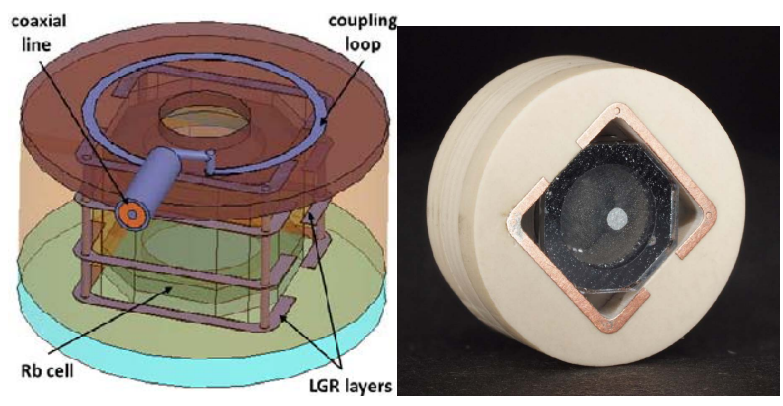

Figure 11 Drawing and assemblage of the $\mu$-LGR containing the microfabricated $\mathrm{Rb}$ vapor cell.

\section{B. DR and stability with $3 D$ cell in miniature cavity}

The combination of the $\mu$-LGR and the $3 \mathrm{D}$-cell gave rise to a clock signal with a contrast of more than $12 \%$ and a linewidth of $5.6 \mathrm{kHz}$ (Figure 12), as well as a figure of merit (FoM) of 20, (as defined in [24] as $10^{6} \mathrm{~Hz} \cdot$ contrast/linewidth $[\mathrm{Hz}])$ and a discriminator slope of $23 \mathrm{pA} / \mathrm{Hz}$. 


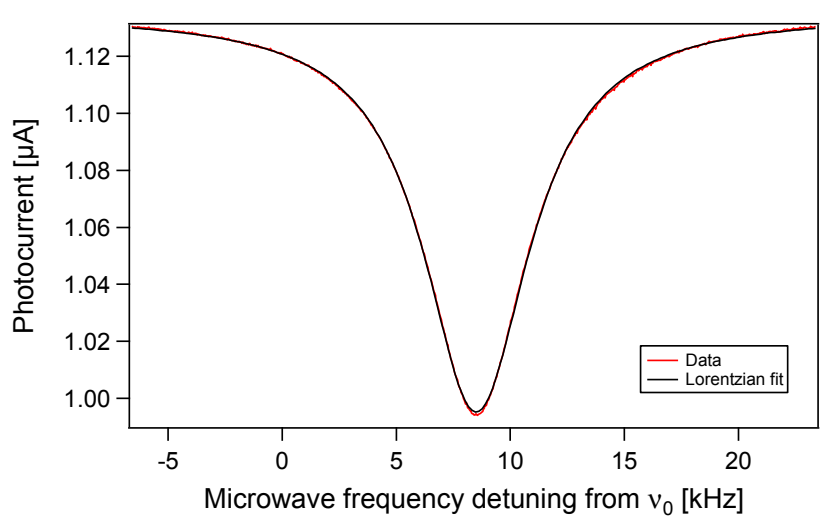

Figure 12. DR signal with 3D cell.

The $\mathrm{S} / \mathrm{N}$ limited short-term stability is estimated around $6.6 \times 10^{-12}$ at $1 \mathrm{~s}$. The measured short-term stability is $7.1 \times 10^{-12} \tau^{-1 / 2}(1-100 \mathrm{~s})$. This short-term stability is better than the best other clocks' using microfabricated cells [8, 10, 20]. The medium- to long-term clock stability is currently limited by a relatively strong intensity-light-shift coefficient of the cell $\left(2.6 \times 10^{-10} / \%\right)$ inducing a substantial temperature sensitivity of $1.1 \times 10^{-9} / \mathrm{K}$. The limit due to the light-shift effect is at the level of $8 \times 10^{-12} @ 10^{4} \mathrm{~s}$ (see Figure 13).

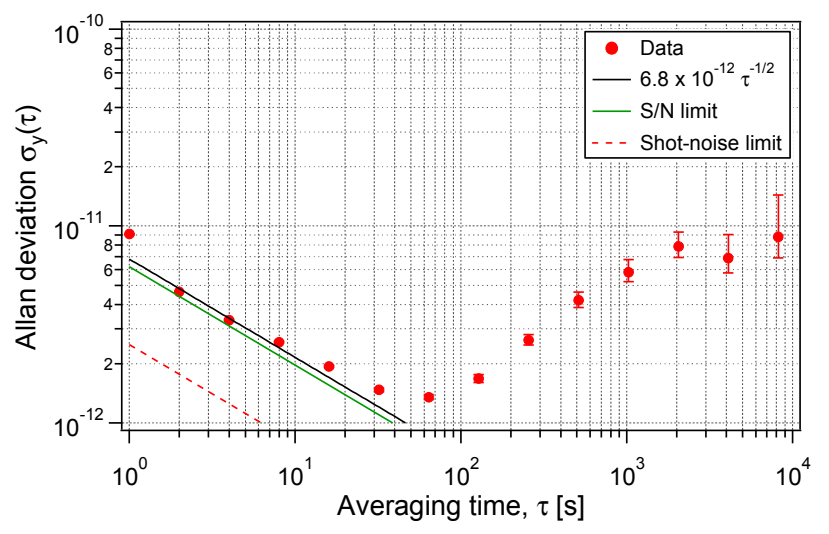

Figure 13. Clock short-term stability with 3D cell.

\section{OTHER CURRENT INVESTIGATIONS}

\section{Wall-coated cells}

As an alternative to the widely used BG technique for increasing the atomic line Q-factor, wall coating remains very interesting for highly compact and miniaturized atomic clocks [25]. Our current researches focus on ripening process of wallcoated cells right after cell production [26] and on intrinsic properties of tetracontane [27]. These studies are carried out in macroscopic (12 $\mathrm{mm}$ inner diameter and length) glass blown cells in view of a future implementation in microfabricated cells. We have shown that the ripening process is mainly a consequence of a reduction of polarization losses [28]. These losses can be attributed to adsorption on the coating or to collisions with uncoated surfaces.

In terms of clock performance, the wall-coated cells give signals with a large contrast $(>30 \%)$ and reasonable linewidth $(<700 \mathrm{~Hz})$. Measured temperature coefficient of $1.5 \times 10^{-10} \mathrm{~K}^{-1}$ (comparable to the values found in literature
$[29,30])$ and intensity light shift coefficients below $1.6 \times 10^{-12} / \%$ are promising for competitive chip-scale and miniaturized clocks. The limitations for a high-performance clock using wall-coated cells were studied in [30].

\section{New miniature clock technologies}

In view of alternative realizations of miniature atomic clocks, we finally mention two recent lines of research. A first line concerns the development of low-temperature cell sealing techniques for micro-fabricated cells. Indeed, the temperatures required for anodic bonding $\left(>250^{\circ} \mathrm{C}\right)$ are currently a critical issue for the production of wall-coated microfabricated cells. An alternative fabrication process based on thin-film Indium bonding technique [31] is currently under investigation. This process allows sealing temperatures of less than $140^{\circ} \mathrm{C}$ only. A buffer-gas-filled microfabricated cell produced with this technique and mounted in a laboratory DR setup provided a clock signal with $5.4 \mathrm{kHz}$ linewidth, demonstrating the suitability of this sealing technology for clock applications. The behavior and aging of the In-bonded cells when operated at elevated temperatures $\left(>60^{\circ} \mathrm{C}\right)$, over extended time, remain to be studied.

The second line concerns the development of a microfabricated $\mathrm{Rb}$ discharge lamp, as an alternative to laser diodes for optical pumping in miniature DR atomic clocks [32]. This approach bears the promise of a much simpler and cheaper micro-fabricated light source than semiconductor lasers. In a first demonstration, a $\mathrm{Rb}$ plasma discharge was created in micro-fabricated 2D cells as presented in section IV-A. Here the radio-frequency drive field is capacitively coupled to the plasma using planar electrodes patterned onto the outside of the cell. Up to $15 \mu \mathrm{W}$ of light power emitted on the Rb D2 line was achieved, which could be used for the optical pumping [33]. Work is in progress to improve on this performance and to demonstrate optical pumping using this micro-fabricated lamp.

\section{CONCLUSIONS}

We have demonstrated the potential of DR in CW operation for $\mathrm{Rb}$ cell frequency standards in compact (highperformance) and miniaturized standards. Two highperformance clock realizations based on $\mathrm{Rb}$ cells with different dimensions were presented. The $25 \mathrm{~mm}$ diameter vapor cell inside a compact LGR exhibits an excellent shortterm stability of $<1.4 \times 10^{-13} \tau^{-1 / 2}$, when operated in laboratory conditions (no vacuum enclosure). This clock has a fundamental shot-noise limit of $5 \times 10^{-14} \tau^{-1 / 2}$ that could be approached by using a laser source with a reduced FM noise or by the noise-subtraction technique [13]. In view of miniaturized DR clocks, a newly designed microfabricated physics package has also been presented. The newly developed $\mu$-LGR microwave resonator has a cavity volume of $<0.9 \mathrm{~cm}^{3}$ and sustains the required microwave field for the clock transition. Our miniaturized DR clock using this $\mu$-LGR exhibits a short-term stability of $7.1 \times 10^{-12} \tau^{-1 / 2}$ ( 1 to $100 \mathrm{~s}$ ).

The discussed alternative technologies, such as wall-coated cell approach, low-temperature thin film Indium bonding (allowing process temperatures $<140^{\circ} \mathrm{C}$ ) and micro-fabricated 
discharge lamps, represent promising approaches to novel high-performance or miniature Rb frequency standards.

\section{ACKNOWLEDGMENTS}

We thank P. Scherler, M. Durrenberger, D. Varidel (all at LTF-UniNe) for their contributions to this work, C. E. Calosso (INRIM, IT) for the LO in high-performance clock, and our Sinergia project partners (SAMLAB-EPFL for developing the microfabricated cells, and LMTS-EPFL for the microfabricated discharge lamps), http://macqs.epfl.ch/ .

\section{REFERENCES}

[1] J. Vanier and C. Mandache, Appl. Phys. B, vol. 87, pp. 565-593, 2007.

[2] C. Affolderbach, G. Mileti, "A compact laser head with high-frequency stability for Rb atomic clocks and optical instrumentation", Rev. Sci. Instrum., vol. 76, p. 073108, 2005.

[3] T. Bandi, C. Affolderbach, C. E. Calosso, and G. Mileti, "Highperformance laser-pumped rubidium frequency standard for satellite navigation", Electron. Lett., vol. 47, pp. 698-699, 2011.

[4] S. Micalizio, A. Godone, C. Calosso, F. Levi, C. Affolderbach and F. Gruet, "Pulsed Optically Pumped Rubidium Clock with High Frequency-Stability Performance", IEEE Trans. Ultrason. Ferroelectr. Freq. Control, vol. 59, pp. 457-462, 2012.

[5] P. Rochat, F. Droz, P. Mosset, G. Barmaverain, Q. Wang, D. Boving, L. Mattioni, M. Belloni, M. Gioia, U. Schmidt, T. Pike, F. Emma, "The Onboard Galileo Rubidium and Passive Maser, Status \& Performance", in Proc. of IEEE IFCS, pp. 26-32 (Vancouver, 2005).

[6] T. Bandi, F. Gruet, C. Affolderbach, C. E. Calosso and G. Mileti, "Investigations on Improved Rb cell standards", in Proc. of the Joint IEEE IFCS and EFTF, no. 7254, pp. 236-238 (San Francisco, 2011).

[7] T. Bandi, C. Affolderbach, C. E. Calosso, C. Stefanucci, F. Merli, A.K.Skrivervik and G. Mileti, "Laser-pumped high-performance compact gas-cell $\mathrm{Rb}$ standard with $<3 \times 10^{-13} \tau^{-1 / 2}$ stability", in Proc. of $26^{\text {th }}$ EFTF, (Göteborg, 2012).

[8] R. Lutwak, A. Rashed, M. Varghesea, G. Tepolt, J. LeBlanc, M. Mescher, D. K. Serkland, K. M. Geib, G. M. Peake and S. Römisch, "The chip-scale atomic clock - prototype evaluation", in Proc. of $21^{\text {st }}$ EFTF (Geneva, 2007) .

[9] S. Knappe, "MEMS atomic clocks" Compr. Microsyst., vol. 3, pp. 571612, 2008.

[10] R. Boudot, X. Liu, E. Kroemer, P. Abbé, N. Passilly, R. K. Chutani, S. Galliou, V. Giordano, C. Gorecki, A. Al-Samaneh, D. Wahl and R. Michalzik, "Characterization of compact CS CPT clocks based on a Cs-Ne microfacricated cell", in Proc. of $26^{\text {th }}$ EFTF (Göteborg, 2012).

[11] R. Lutwak, D. Emmons, W. Riley and R. M. Garvey, "The chip-scale atomic clock - coherent population trapping vs. conventional interrogation", in Proc. of the 34th PTTI Meeting, (Reston, 2002).

[12] R. H. Dicke, Phys. Rev. vol. 89, p. 472, 1953.

[13] C. Affolderbach, T. Bandi, R. Matthey, F. Gruet, M. Pellaton, G. Mileti, "Compact, High-Stability Rb Atomic Clocks for Space", in Proc. of the $3^{\text {rd }}$ International Colloquium - Scientific and Fundamental Aspects of the Galileo Programme, in ESA proc. WPP-326, paper 1400 (Copenhagen, 2011).

[14] C. Affolderbach, F. Gruet, R. Matthey and G. Mileti, "A compact laserpumped $\mathrm{Rb}$ clock with $5 \times 10^{-13} \tau^{-1 / 2}$ frequency stability", in Proc. of the Joint IEEE IFCS and EFTF, no. 7254, pp. 944-946, (San Francisco, 2011).

[15] C. Stefanucci, T. Bandi, F. Merli, M. Pellaton, C. Affolderbach, G. Mileti and A. K. Skrivervik, "Compact microwave resonator for highperformance rubidium frequency standards", submitted to Rev. Sci. Instrum.

[16] R. Matthey, C. Affolderbach, G. Mileti, "Methods and evaluation of frequency aging in DFB laser diodes for Rubidium atomic clocks", Opt. Lett. , vol. 36, No. 17, pp. 3311-3313, 2011.
[17] C. E. Calosso, F. Levi, E. K. Bertacco, A. Godone, and S. Micalizio, "Low-Noise Electronic Design for the ${ }^{87} \mathrm{Rb}$ Coherent Population Trapping Maser", IEEE Trans. Ultrason. Ferroelectr. Freq. Control, vol. 52, no. 11, pp. 1923-1930, 2005.

[18] J. C. Camparo, "Conversion of laser phase noise to amplitude noise in an optically thick vapor," J. Opt. Soc. Am. B, vol. 15, pp. 1177-1186, 1998.

[19] G. Mileti, J. Deng, F. L. Walls, D. A. Jennings, R. E. Drullinger, "Laser-Pumped Rubidium Frequency Standards: New Analysis and Progress", J. Quantum Electronics, vol. 34, pp. 233-237, 1998.

[20] A. M. Braun, T. J. Davis, M. H. Kwakernaak, J. J. Michalchuk, A Ulmer, W. K. Chan, J. H. Abeles, Z. A. Shellenbarger, Y-Y. Jau, W. Happer, T. McClelland, H. Fruehauf, R. Drap, W. Weidemann and M. Variakojis, "RF-interrogated end-state chip-scale atomic clock" in Proc. of the $39^{\text {th }}$ PTTI Meeting (Long Beach, 2007).

[21] M. Pellaton, C. Affolderbach, Y. Pétremand, N. F. de Rooij and G. Mileti, "Study of laser-pumped double-resonance clock signals using a microfabricated cell” Phys. Scr., T149, p. 014013, 2012.

[22] Y. Pétremand, C. Affolderbach, R. Straessle, M. Pellaton, D. Briand, G. Mileti, N. F. de Rooij, Microfabricated rubidium vapour-cell with a thick glass core for small scale atomic clock applications, J. Micromech. Microeng., vol. 22, p. 025013,2012.

[23] M. Violetti, C. Affolderbach, F. Merli, J.-F. Zürcher, G. Mileti and A. K. Skrivervik, "Miniaturized Microwave Cavity for Rubidium Atomic Frequency Standards",submitted to the European Microwave Week 2012 (EuMW2012), Amsterdam RAI, The Netherlands, Oct. 28- Nov. 2, 2012. See also: M. Violetti et al. "Microwave resonator, Quantum Sensor, and Atomic Clock", European Patent Application ${ }^{\circ} 12155696$, 16 February 2012.

[24] J. Deng, P. Vlitas, D. Taylor, L. Perletz, and R. Lutwak, "A commercial CPT Rubidium clock", in Proc. of $22^{\text {nd }}$ EFTF (Toulouse, 2008).

[25] J. Kitching, S. Knappe and L. Hollberg, "Miniature vapor-cell atomicfrequency references", Appl. Phys. Lett., vol. 81, p. 553, 2002.

[26] J. C. Camparo, R. P. Fruholz and B. Jaduszliwer, "Alkali Reactions With Wall Coating Materials Used in Atomic Resonance Cells" J. Appl. Phys., vol. 62, pp. 676-681, 1987.

[27] D. Budker, L. Hollberg, D. F. Kimball, J. Kitching, S. Pustelny, and V. V. Yashchuk, "Investigation of microwave transitions and nonlinear magneto-optical rotation in anti-relaxation-coated cells", Phys. Rev. A vol. 71, p. 012903, 2005.

[28] M. Pellaton, R. Straessle, C. Affolderbach, D. Briand, N. de Rooij and G. Mileti, Wall-coated cells for Rb atomic clocks: Study of the ripening process by double-resonance spectroscopy, in Proc. of $26^{\text {th }}$ EFTF (Göteborg, 2012).

[29] E. Breschi, G. Kazakov, C. Schori, G. Di Domenico, G. Mileti, A. Litvinov and B. Matisov, "Light effects in the atomic-motion-induced Ramsey narrowing of dark resonances in wall-coated cells," Phys. Rev. A, vol. 82, p. 063810, 2010.

[30] T. Bandi, C. Affolderbach and G. Mileti, "Laser-pumped paraffincoated cell $\mathrm{Rb}$ frequency standard", J. Appl. Phys., In press.

[31] R. Straessle, M. Pellaton, Y. Pétremand, D. Briand, C. Affolderbach, G. Mileti and N.F. de Rooij, "Low-temperature Indium hermetic sealing of alkali vapor-cells for chip-scale atomic clocks" in Proc. of IEEE MEMS (Paris, 2012).

[32] V. Venkatraman, Y. Pétremand, C. Affolderbach, G. Mileti, N. F. de Rooij, H. Shea, "Microfabricated chip-scale rubidium plasma light source for miniature atomic clocks", IEEE Trans. Ultrason. Ferroelectr. Freq. Control, vol. 59, no. 3, pp. 448 - 456, 2012.

[33] S. Wang, L. Lin, and H. Guo, "Analysis and design of a micromachined $\mathrm{Rb}-85$ filter in passive rubidium atomic clock", in Proc. of 4th IEEE Int. Conf. on Nano/Micro Engineered and Molecular Systems, pp. 911914 (Shenzhen, China, 2009). 